ISSN 2179-6750

\title{
Parto humanizado e interdisciplinaridade: um olhar sobre a saúde da mulher e da criança a partir da experiência de trabalho do Hospital Sofia Feldman
}

\author{
Fernanda Mitre Cotta, Ana Paula da Silva Amaral, Priscila Gonçalves Resende Chaves
}

\begin{abstract}
Resumo
Segundo a Organização Mundial de Saúde (OMS), o Brasil é o país campeão de cirurgias cesarianas no mundo $-82 \%$ na rede particular e $37 \%$ na pública; mais que o dobro do recomendado que é de 15\%. Além dos riscos da cirurgia, estas acabam impedindo medidas que fazem bem para o binômio mãe-bebê, como amamentação na primeira hora e clampeamento tardio do cordão umbilical. Nesta linha, o Hospital Sofia Feldman (HSF), tem como objetivo, prestar atendimento pelo SUS, com qualidade, de forma interdisciplinar e humanizado. Apresentar os dados de atendimento do HSF, cuja missão é desenvolver ações de atenção integral à saúde da mulher e da criança, com qualidade e resolutividade, de forma universal, visando impactar nos indicadores de saúde deste grupo. Estudo de caso, com apresentação dos indicadores, segundo a série histórica dos anos de 2013, 2014 e 2015, respectivamente, elaborados de acordo com o item 5 do Termo de Compromisso das Maternidades do SUS-BH estabelecido pela Comissão Perinatal da Secretaria Municipal de Saúde de Belo Horizonte. O HSF assiste a uma população superior a 400 mil pessoas. O total de partos realizados nos anos de 2013, 2014 e 2015 foram de 11.020, 11.271 e 11.471 respectivamente; destes $24,7 \%, 24,9 \%$ e 24,0\% foram cesáreas, destaca-se que apesar de ser superior ao recomendado pela OMS, o HSF atende a uma grande porcentagem de gestantes de alto risco e só indica partos cesário quando a gestante é iterativa ou quando há indicação materna ou fetal; quanto aos partos normais, $18,6 \%, 21,9 \%$ e $22 \%$ foram assistidos por médicos enquanto $81,4 \%, 78,1 \%$ e $78 \%$ por enfermeiros; referente a Episiotomia destaca-se que apenas foi realizado 5,8\%, 3,6\% e 3,1\%; relativo a interação mãe/filho na sala de parto, ocorreu em $86,1 \%, 86,7 \%$ e $86.6 \%$ dos partos, a taxa de ocupação instalada na maternidade foi $98,1 \%, 100,5 \%$ e $96,7 \%$, e a mortalidade materna foi de 3,5 e 2 , respectivamente. Na maternidade, a equipe multi e interdisciplinar oferece atenção humanizada, buscando favorecer os laços mãe, filho e família através de ações como: ênfase na imagem do parto normal como uma forma prazerosa, segura e saudável de dar à luz; o empoderamento e valorização da mulher pela conscientização de seus direitos; o envolvimento do homem-pai no processo de nascimento; a presença de um acompanhante da escolha da mulher durante o trabalho de parto; a valorização da atenção da(o) enfermeira(o) obstetra; a segurança e o apoio das Doulas; o incentivo a promoção do aleitamento materno; a valorização de uma rede de proteção social ao recém-nascido e a mãe e a internação conjunta para mães e filhos em alojamento conjunto.
\end{abstract}

Descritores: Parto humanizado; Saúde da mulher; Trabalho interdisciplinar 